\title{
Let's work together to make breastfeeding work!
}

The global recommendation on the early initiation of breastfeeding, exclusive breastfeeding (EBF) for six months, and continued breastfeeding for up to two years of age and beyond, ${ }^{1}$ remains uncontested. ${ }^{2-4}$ However, the translation of this recommendation into successful practice continues to fall short. ${ }^{5}$

In the run up to the announcement of the sustainable development goals in September 2015, and in a bold step to set the scene for new nutrition goals, the World Health Assembly (WHA) adopted six nutrition targets for $2025 .{ }^{6}$ One of these is to increase the rate of EBF in the first six months of life up to at least $50 \%{ }^{6}$ However, achieving the WHA target is slow and uneven at global level, and modest progress only has been made with respect to the target to increase EBF rates. ${ }^{5}$

When reflecting on breastfeeding in the global context, the question arises: "Why is progress on improving the breastfeeding rate, and especially the EBF rate, so uninspiring?" The answer can be found in recognition that successful infant and young child nutrition (IYCN), with breastfeeding as a core component, is ultimately dependent upon a range of immediate, underlying and basic determinants of nutritional status. ${ }^{7}$ Interventions in each of the three areas should be mutually supportive in order to realise improved nutrition. This complexity of addressing IYCN may explain why targets remain out of reach, even though many of the solutions are known today. ${ }^{8}$

Nevertheless, country examples, including Bangladesh and Brazil, Cuba and Togo, indicate that rapid progress on improving EBF rates is possible..$^{5}$ The overarching success of interventions points to a multidimensional approach that draws different sectors, levels and stakeholders together. ${ }^{5}$ It is suggested from the evidence that improvements can be achieved if stakeholders work strategically, effectively, in alliance, at scale, and with accountability; ${ }^{5}$ essentially adopting a "whole of society approach". 9,10

Interventions can be successful if investment is made central to applicable programmes, policies and action plans, including nutritionspecific and nutrition-sensitive interventions supported by enabling environments. ${ }^{11,12}$ The latter address the basic determinants of nutritional status, such as governance, income and equity, which are expressed in the form of laws, regulations and policies; investment in economic growth, and improvement in governance capacity. ${ }^{12}$ Improvement in nutritional status ultimately results from efforts from these three areas. The most powerful blend of these three areas, and the relative contribution from each context, in addressing IYCN, including breastfeeding, is still to be determined. ${ }^{5}$

Persistently low EBF rates on the African continent are confirmed by three featured articles in this issue of the South African Journal of Clinical Nutrition. ${ }^{13-15}$ In South Africa, the EBF rate for infants aged six months and younger is reported to be $\sim 8 \% .{ }^{16}$ Persistent constraints to EBF for six months cited by mothers in the three featured articles, which correspond with the findings in the literature, ${ }^{17-21}$ include lack of knowledge, the perceived insufficiency of breastmilk to satisfy an infant's needs, cultural practices and societal influences. ${ }^{13-15}$ Healthcare workers are repeatedly cited as the most utilised and trusted source of infant and young child feeding (IYCF), ${ }^{13,14}$ a finding that is also supported by previous literature. ${ }^{22-25}$
A recent independent report, the Evaluation of nutrition interventions for children from conception to age 5 in South Africa, ${ }^{26}$ assessed breastfeeding support to mothers as a key nutrition intervention strategy. Breastfeeding was found to be a prioritised nutrition intervention, and education and counselling were reported to be integrated into maternal, neonatal, child and women's health policies and services, including better ante-natal care, the prevention of mother-to-child transmission of human immunodeficiency virus (HIV), and maternity and postnatal services. However, implementation seems to be constrained by poorquality counselling, including nurses' weak knowledge and skills (required to directly support breastfeeding behaviour), the inconsistent training of health workers on breastfeeding, healthcare staff shortages, and suboptimal monitoring and evaluation. ${ }^{26}$

The situation in KwaZulu-Natal province, highlighted as having made good progress on nutrition outcomes since 2003, was the exception to this finding. Nurses in health facilities in KwaZulu-Natal demonstrated good knowledge of the main nutrition counselling messages, including EBF for six months, continued breastfeeding, and breastfeeding during illness. More than $80 \%$ of KwaZulu-Natal nurses could recall the correct message for different scenarios, in comparison to only $50 \%$ of nurses in three other evaluated provinces in the country. ${ }^{26}$ Furthermore, the KwaZulu-Natal provincial Department of Health initiated a programme, similar to the Brazil model, ${ }^{27}$ which entails the placement at primary healthcare level of former community caregivers trained in nutrition, and skilled in providing nutrition support and non-clinical interventions, with a strong focus on breastfeeding. ${ }^{26}$

The findings from the articles on breastfeeding featured in this journal issue suggest that the implementation of the Mother Baby Friendly Initiative (MBFI), formerly known as the Baby-Friendly Hospital Initiative, could improve early breastfeeding initiation, as well as a longer EBF period. ${ }^{13}$ The promotion of strong, community-based support networks through both governmental and non-governmental organisations were also found to improve breastfeeding practices. ${ }^{14}$

More ingredients in the KwaZulu-Natal success story relate to good interdepartmental coordination and service linkage, partnerships with non-governmental organisations, a more appropriate budget for nutrition, and a clear vision and commitment to the implementation of nutrition action. The fact that nutrition was elevated to the directorate level of management is the one feature which separates KwaZulu-Natal from the rest of the provinces in the country. This position provides a higher leadership profile and power base, compared to that in other provinces, where the nutrition programme is managed at subdirectorate level. The realisation of this success factor in KwaZulu-Natal prompted one of the key recommendation in the evaluation report, i.e. "Elevating nutrition to an output should be accompanied by giving responsibility for nutrition to at least a cluster manager in national $\mathrm{DoH}$ and to a directorate level at provincial DoH". ${ }^{26}$

A further recommendation in this evaluation report was that the national Department of Health should create a specific, well-defined, dedicated health promotion and communication strategy on nutrition for infants aged five years and younger, as was achieved for HIV/acquired immune 
deficiency syndrome. The use and development of relevant multimedia and materials, including television and radio, to educate pregnant women on the importance of optimal nutrition of infants aged five years and younger, and the use of celebrities to raise the status of breastfeeding, was also suggested. ${ }^{26}$

Legislation and policies concerning IYCN should also be assessed for their impact on creating a broader enabling environment for improved breastfeeding. It is too early to determine the influence of Regulation 9910n IYCF and IYCN in South Africa, ${ }^{28}$ since the full scope of legislation only came into effect in 2015, but the impact should be evaluated soon. Challenges for working mothers to breastfeed in the workplace, including insufficient maternity leave and facilities at work which are unsupportive of breastfeeding, are other legislative and policy issues needing urgent attention. $^{25}$

Nutrition, with breastfeeding as the ultimate foundation, must be seen and understood as both an input to and an outcome of sustainable development, in the broader development context. ${ }^{29}$ The importance of nutrition in the fight to eliminate poverty and reduce inequality is emphasised in South Africa's National Development Plan. Nutrition, with specific inclusion of breastfeeding support, features prominently in the plan. Nutrition is explicitly linked to elements of a decent standard of living, with an emphasis on women and children. The plan states that the set goals can be realised in South Africa by drawing on the energies of the people ${ }^{30}$ resonating with the adoption of a "whole of society approach". 10,30

The success stories and the interventions which have been shown to improve EBF and continued breastfeeding ${ }^{5,26}$ indicate a blended approach, and draw on interventions at various levels and by multiple stakeholders. An urgency to make these interventions work should be created, and the Tshwane declaration's call to every citizen to promote, protect and support breastfeeding must be communicated afresh. ${ }^{24,26}$ Research should guide us further to show which interventions and combinations of interventions have yielded the most powerful results in the country. ${ }^{5}$ Good leadership should inspire us to remember why we choose to devote our professional lives to nutrition, and for many, to improving IYCN in particular. So, let's embrace the lessons from far and near, and make a renewed and united pledge to make breastfeeding work!

Lisanne du Plessis, MNutrition, RD(SA), NT(SA)

Senior Lecturer, Community Nutrition, Division of Human Nutrition, Faculty of Medicine and Health Sciences, Stellenbosch University, Stellenbosch, South Africa

E-mail: Lisanne du Plessis, e-mail: Imdup@sun.ac.za

\section{References}

1. World Health Organization. Global strategy for infant and young child feeding. Geneva: WHO, 2003.

2. Kramer MS, Kakuma R. Optimal duration of exclusive breastfeeding. [Cochrane review] In: The Cochrane Library, Issue 1, 2002, Issue 1. Oxford: Update Software.

3. Bhutta ZA, Ahmed T, Black RE, et al. What works? Interventions for maternal and child undernutrition and survival. Lancet. 2008:371(9610):417-440.

4. Becker GE, Remmington S, Remmington T. Early additional food and fluids for healthy breastfed full-terminfants. [Cochrane review]. In: The Cochrane Library, Issue 12, 2011. Oxford: Update Software.

5. International Food Policy Research Institute. Global nutrition report 2014: actions and accountability to accelerate the world's progress on nutrition. Washington, DC: International Food Policy Research Institute, 2014.

6. World Health Organization. Global targets 2025. WHO [homepage on the Internet]. 2015 c2015. Available from: http://www.who.int/nutrition/topics/nutrition_globaltargets2025/ en/

7. United Nations Children's Fund. Strategy for improved nutrition of children and women in developing countries. UNICEF [homepage on the Internet]. 1990. c2015. Available from: http://www.ceecis.org/iodine/01_global/01_pl/01_01_other_1992_unicef.pdf

8. Harris J, Drimie S. Toward an integrated approach for addressing malnutrition in Zambia: a literature review and institutional analysis. Washington, DC: International Food Policy Research Institute, 2012

9. Dube L, Pingali P, Webb P. Paths of convergence for agriculture, health, and wealth. Proc Natl Acad Sci USA. 2012;109(31):12294-12301.

10. World Health Organization. Whole-of-society-pandemic readiness: WHO guidelines for pandemic preparedness and response in the non-health sector. WHO [homepage on the Internet]. 2009. c2015. Available from : http://www.who.int/influenza/preparedness/ pandemic/2009-0808_wos_pandemic_readiness_final.pdf [2015, 24 July].

11. Black RE, Victora CG, Walker SP, et al. Maternal and child undernutrition and overweight in low-income and middle-income countries. Lancet. 2013;382(9890):427-451.

12. Gillespie S, Haddad L, Mannar V, et al. The politics of reducing malnutrition: building commitment and accelerating progress. Lancet. 2013;382(9891):552-569.

13. Van der Merwe S, Du Plessis L, Jooste H, Nel D. Comparison of infant-feeding practices in two health subdistricts with different baby-friendly status in Mpumalanga province. $S$ Afr J Clin Nutr. 2015;28(3):Xx-xx

14. Stolkie, et al . S Afr J Clin Nutr. 2015(3)xx-xx.

15. Tamiru D Tamrat M. Constraints to the optimal breastfeeding practices of breastfeeding mothers in the rural communities of Arba Minch Zuria Woreda, Ethiopia: a communitybased, cross-sectional study. S Afr J Clin Nutr. 2015;28(3):134-139.

16. Mhlanga RE. Maternal, newborn and child health: 30 years on. South African health review 2008.. Health Systems Trust [homepage on the Internet]. 2008. c2015. Available from: http://www.hst.org.za/publications/841

17. Macintyre UE, de Villiers FPR, Baloyi PG. Early infant feeding practices of mothers attending a postnatal clinic in Ga-Rankuwa. S Afr J Clin Nutr. 2005;18(2):70-75

18. Doherty TM, McCoy D, Donohue S. Health system constraints to optimal coverage of the prevention of mother-to-child HIV transmission programme in South Africa: lessons learned from the implementation of the national pilot programme. Afr Health Sci. 2005;5(3):213-218.

19. Murtaugh MA. Nutrition during lactation. Nutrition through the lifecycle. In: Brown JE, editor. California: Wadsworth, 2002, p. 135-189.

20. Savage King, F. Helping mothers to breastfeed. Nairobi: African Medical and Research Foundation, 1992

21. Doherty T, Chopra M, Jackson D, et al. Effectiveness of the WHO/UNICEF guidelines on infant feeding for HIV-positive women: results from a prospective cohort study in South Africa. AIDS. 2007;21(13):1791-1797.

22. Kassier SM, Veldman FJ. Cry, the beloved bottle: infant-feeding knowledge and the practices of mothers and caregivers in an urban township outside Bloemfontein, Free State province. S Afr J Clin Nutr. 2013;26(1):17-22.

23. Davies A. PMTCT: how "informed "is the literate mother's decision regarding infant feeding options in the Gert Sibande district, Mpumalanga province, South Africa [published dissertation]. Stellenbosch: Stellenbosch University; 2005.

24. Doherty T, Chopra M, Nkonki L, et al. Effect of the HIV epidemic on infant feeding in South Africa: "When they see me coming with the tins they laugh at me". Bull World Health Organ. 2006;84(2):90-96.

25. Tshwane declaration for the support of breastfeeding in South Africa. S Afr J Clin Nutr. 2011;24(4).

26. Department of Health, Department of Social Development and Department of Performance, Monitoring and Evaluation. South Africa. Diagnostic/implementation evaluation of nutrition interventions for children from conception to age 5 . The Presidency, Republic of South Africa. Department of Performance Monitoring and Evaluation [homepage on the Internet]. 2014. c2015. Available from: http://evaluations. dpme.gov.za/sites/EvaluationsHome/Evaluations/Forms/Evaluations\%20View. aspx?RootFolder=\%2Fsites $\% 2$ FEvaluationsHome $\% 2$ FEvaluations $\% 2$ FDiagostic $\% 20$ Implementation $\% 20$ Evaluation $\% 20$ of $\% 20$ Nutrition $\% 20$ Intervention $\% 20$ of $\% 20$ Children\%20from \%20Conception $\% 20$ to $\% 20$ Age $\% 205 \% 2$ FFinal $\% 20$ Report $\% 20$ \%281525\%29\%20Includes\%20Exec\%20Summary\&InitialTabld=Ribbon\%2EDocument \&VisibilityContext=WSSTabPersistence

27. Du Plessis LM. Infant and young child feeding in South Africa: stop the crying beloved country. S Afr J Clin Nutr. 2013;26(1):4-5.

28. Foodstuffs, Cosmetics and Disinfectant Act, No 54 of 1972. Regulation 991. Pretoria: Government Printers, 2012

29. International Council for Science, International Social Science Council. Review of the sustainable development goals: the science perspective. Paris: ICSU, 2015.

30. National Planning Commission. National Development Plan 2030: our future - make it work. South African Government [homepage on the Internet]. 2012. c2015. Available from: http://www.gov.za/issues/national-development-plan-2030 